\title{
AGRICULTURA DE BASE ORGÂNICA E AGROECOLÓGICA: CARACTERIZAÇÃo SOCIAL E PERCEPÇÃO DOS CONSUMIDORES EM FEIRAS LIVRES DE MACEIÓ-AL
}

\author{
SILVA, João Manoel da ${ }^{1}$ \\ NASCIMENTO, Sheylla Patrícia Gomes do ${ }^{2}$ \\ ARAÚJO, Romário Guimarães Verçosa de ${ }^{3}$ \\ LIMA, Jessé Rafael Bento de ${ }^{4}$ \\ SILVA, Clayton dos Santos ${ }^{5}$ \\ SANTOS, Tania Marta Carvalho dos ${ }^{6}$ \\ COSTA, Jakes Halan de Queiroz ${ }^{7}$
}

\begin{abstract}
Recebido em: $2020.09 .16 \quad$ Aprovado em: $2021.04 .29 \quad$ ISSUE DOI: $10.3738 / 1982.2278 .3842$
RESUMO: Objetivou-se por meio desse estudo desenhar o perfil social de consumidores de feiras livres em Maceió, Alagoas, Brasil, bem como compreender como estes percebem agricultura de base agroecológica e orgânica. Como procedimento metodológico foi adotado abordagem qualitativa e quantitativa, tendo como apoio a aplicação de questionários, os quais foram aplicados in loco de modo aleatório durante a realização das feiras. Os dados obtidos foram tabulados e expressos em porcentagem sob a amostra total e os dados qualitativos foram interpretados com base na literatura específica. Assim, as feiras livres observadas demonstram que seus consumidores apresentam todos os níveis de escolaridade e faixas etárias, sendo a maioria desses frequentadores do gênero feminino, entre 20-24 e 45-69 anos. A medida das faixas etárias examinadas corroboram que, quanto mais novo o consumidor maior o nível de escolaridade. Dos entrevistados, 89,44\% expõem a importância da redução no uso de agrotóxicos ao associá-los com a produção de alimentos e os danos causados, como doenças respiratórias e de pele, representando 78,9\% dos entrevistados. Esses dados mostram a importância da articulação da discussão sobre essas bases de se fazer agricultura e o reconhecimento de suas diferenças reafirmando o espaço de produção e reprodução da sociedade e o desenvolvimento de práticas mais sustentáveis.
\end{abstract}

Palavras-chave: Saberes saudáveis. Qualidade alimentar. Rurbanidade.

\section{AGRICULTURE FROM ORGANIC AND AGROECOLOGICAL BASIS: SOCIAL CHARACTERIZATION AND PERCEPTION OF CONSUMERS IN FREE FAIRS IN MACEIÓ-AL}

SUMMARY: The objective of this study was to draw the social profile of consumers of open markets in Maceió, Alagoas, Brazil, as well as to understand how they perceive agroecological and organic agriculture. To this end, a qualitative and quantitative approach was adopted as a methodological procedure, supported by the application of questionnaires, which were applied in locu at random during the fairs. The data obtained were tabulated and expressed as a percentage under the total sample and the qualitative data were interpreted based on the specific literature. Thus, the observed free fairs demonstrate that their consumers have all levels of education and age groups, with the majority of these women being between 20-24 and 45-69 years old. The measurement of the age groups examined corroborate that the younger the consumer, the higher the level of education. Of the interviewees, $89.44 \%$ expose the importance of reducing the use of pesticides when associating them with food production and the damage caused, such as respiratory and skin diseases, representing $78.9 \%$ of the interviewees. These data show the

\footnotetext{
${ }^{1}$ ORCID ID - http://orcid.org/0000-0002-7654-5475 Engenheiro Agrônomo, Mestre em Ciências. Rede Nordeste de Biotecnologia, Instituto de Química e Biotecnologia, Universidade Federal de Alagoas.

${ }^{2}$ ORCID ID - http://orcid.org/0000-0001-7404-2332 Programa de Pós-Graduação em Geografia, Universidade Federal de Sergipe

${ }^{3}$ ORCID ID http://orcid.org/0000-0001-6150-9829 Programa de Pós-Graduação em Proteção de Plantas, Campus de Engenharias e Ciências Agrárias, Universidade Federal de Alagoas

${ }^{4}$ ORCID ID http://orcid.org/0000-0003-3439-8697 Programa de Pós-graduação em Desenvolvimento e Meio

Ambiente, Universidade Federal de Pernambuco

${ }^{5}$ ORCID ID http://orcid.org/0000-0003-3924-5526 Programa de Pós-graduação em Desenvolvimento e Meio Ambiente, Universidade Federal de Pernambuco

${ }^{6}$ ORCID ID http://orcid.org/0000-0002-1816-7840 Campus de Engenharias e Ciências Agrárias, Universidade Federal de Alagoas

${ }^{7}$ ORCID ID http://orcid.org/0000-0002-0018-9646 Campus de Engenharias e Ciências Agrárias, Universidade Federal de Alagoas
}

Nucleus, v.18, n.1, abr. 2021 
importance of articulating the discussion on these bases of farming and the recognition of their differences, reaffirming the space of production and reproduction of society and the development of more sustainable practices.

Keywords: Healthy knowledge. Food quality. Rrurbanity.

\section{INTRODUÇÃO}

Há tempos, a sociedade vem buscando maneiras mais saudáveis e sustentáveis de obtenção de alimentos, especialmente com a grande expansão de áreas agrícolas. Outro fenômeno é a rurbanidade, como mostrado por Almeida et al. (2018), sendo este um fator essencial no tocante da busca de alimentos mais frescos e saudáveis, uma vez que moradores de zonas rurais quando da migração para ambientes urbanos tendem a buscar esse tipo de alimento, o que nem sempre ocorre com aqueles que já nasceram no urbano e não tiveram contatos diretos com qualquer forma de cultivo de plantas.

Nesse aspecto, salienta-se aqui a necessidade de se compreender as ramificações da agricultura, que passou por transformações ao longo do tempo, desde a revolução verde, que nos proporcionou uma imensidão de tecnologias que visaram e proporcionaram o crescimento exponencial da produtividade agrícola em todo o mundo. Porém, esse conhecido "pacote tecnológico"e a possibilidade de circulação mundial da produção por ele incrementado (PAULINO; ALMEIDA, 2010), também ocasionou impactos ambientais em vários ecossistemas, especialmente por meio do uso indiscriminado de produtos químicos (agroquímicos, agrotóxicos), que foram usados em larga escala sem que houvesse uma prospecção de impactos que pudessem acometer os ecossistemas e também a população. Ademais, a agricultura, em todas as suas dimensões e ramificações, é o setor da economia que mais move capital além de estar intrinsecamente relacionada ao meio ambiente direta e indiretamente (SILVA et al., 2020).

Logo, é preciso conhecer essas ditas ramificações - agronegócio, agroecologia, produção orgânica -, pois muitas correntes, especialmente o que se hospeda nas mídias, propagam ideais e teorias errôneas acerca dessas formas de agricultura (ROCHA; TALGA, 2016). Para Rufino (1999), o conceito de agronegócio surgiu a partir da integração da agricultura aos setores industriais de fornecimento de insumos, de um lado, e de processamento e distribuição da produção, de outro. Assim, este abrange todas as transformações associadas aos produtos agrícolas (incluindo também segmentos na produção animal), desde a produção de insumos, passando pela unidade agrícola, processamento e distribuição até o consumidor final.

Desse modo, a partir de uma crítica aos sistemas convencionais de produção e de um amplo consenso em relação à viabilidade de se reconstruir a atividade agropecuária em bases ecológicas, a multiplicidade de iniciativas por parte de diferentes instituições e atores envolvidos 
com inovações e transições em variados contextos contribuiu para a eclosão de múltiplos significados para a noção de Agroecologia (BRANDENBURG, 2002; NORDER et al., 2016).

A agroecologia, por sua vez, possui uma proposta de produção e consumo conscientes, que ocorra de modo regional e livre do uso de agroquímicos, objetivando a promoção do uso integrado de recursos naturais e a produção de alimentos juntamente com a biodiversidade, a sociedade e a cooperação (IANAMOTO; TAVARES; FREIXÊDA, 2012). Para Ormond et al. (2002) a agricultura orgânica pode ser definida como um conjunto de processos da produção agrícola partindo do suposto básico de que a fertilidade é uma função direta da matéria orgânica do solo, o que remete à manutenção dessa fertilidade revertida, em seguida, em alimentos saudáveis.

Conforme assinala Primavesi (1997) a agricultura ecológica, a qual conhecemos hoje como agroecologia, é uma perspectiva que possui o intuito de restabelecer o ambiente como um todo, especialmente no que trata do solo. Isso se dá pela necessidade de não apenas produzir alimentos em larga escala, mas manter a sanidade do solo para que se possa assegurar segurança alimentar para as descendências.

De acordo com Aquino e Assis (2005), o emprego mais antigo da palavra agroecologia diz respeito ao zoneamento agroecológico, que é a demarcação territorial da área de exploração possível de uma determinada cultura, em função de caracteres edafoclimáticos específicos. Segundo Altieri (1989) é uma ciência emergente, a qual estuda os agroecossistemas, interatuando saberes da agronomia, ecologia, economia e sociologia. Nesse sentido, Aquino e Assis (2005) tratam da agroecologia como uma ciência emergente que está em construção alicerçada em conhecimentos interdisciplinares que envolvem várias ciências. Assim também define Candiotto (2020) ao explanar os conceitos de agroecologia, onde o autor a define como sendo, sobretudo, uma construção social em fase inicial, permeada por uma heterogeneidade de pensamentos e ações, e inacabada.

Portanto, a noção de Agroecologia passou a ser empregada por um número crescente de instituições e em diversos países. Isso levou a uma expressiva polissemia e em alguns casos encontram-se críticas à sua imprecisão e às confusões geradas em determinados espaços de debate acadêmico e político (NORDER et al., 2016).

A partir da década de 20, diversos movimentos, com base conceitual abrangente, reuniamse sob a denominação genérica de agricultura alternativa, englobando diversas correntes tais como: agricultura orgânica, natural, biodinâmica, ecológica, biológica, regenerativa e permacultura (JESUS, 1996; CAMPANHOLA; VALARINI, 2001). Embora apresente suas peculiaridades, ficaram conhecidas no Brasil como sinônimos de agricultura orgânica, na medida em que esta agricultura se tornou a corrente mais difundida. A partir dos anos 1980, a base 
científica para estes movimentos foi dada pela agroecologia, ciência em construção, que apresenta uma série de princípios e metodologias para estudar, analisar, dirigir, desenhar e avaliar agroecossistemas (ALTIERI, 1989; CANDIOTTO, 2020).

Ainda mais importante que conhecer teorias e conceitos acerca das linhas de agriculturas, as quais são importantes para a sociedade, salienta-se conhecer e aprofundar no cenário da pesquisa, as feiras livres nas quais são frequentadas sistematicamente pelas populações, a fim de se obter produtos das mais variadas formas. Estas são caracterizadas como uma forma mercantil, tendo em vista que comercializam uma diversidade de produtos diferenciados. Algumas feiras livres apresentam determinadas singularidades, como manufaturados (vestuários e eletrônicos), produtos usados e animais vivos, geralmente galinhas e outros animais de criação direcionados a alimentação. Na cidade de Maceió, as principais feiras, segundo (ALMEIDA; FERREIRA NETO, 2017) por se tratarem das que possuem maior área e diversidade de produtos comercializados, são distribuídas em três: Tabuleiro do Martins, Complexo Benedito Bentes, ambas localizadas na parte alta da cidade, concebida como tabuleiros costeiros, seguida da feira do Jacintinho, ambas localizadas na região denominada Área de Expansão de Maceió, conforme descrevem Almeida e Ferreira Neto (2017).

O destaque é o bairro Tabuleiro do Martins que concentra três feiras livres, seguido do Complexo Benedito Bentes, com duas feiras. As demais feiras se concentram na parte baixa da cidade, em Bebedouro, no Jacintinho, Jaraguá e Jatiúca (ANDRADE, 2012; ALMEIDA; FERREIRA NETO, 2017).

As feiras livres são uma tradicional modalidade, geralmente periódica, de comércio varejista, dispersas no espaço e no tempo, cada qual com a sua relevância peculiaridade. Esses aspectos culminam para que sua importância seja ressaltada, pois, uma feira livre é um local que vai além da troca de mercadorias e capital, mas torna-se um lugar de magnitude social, permeada pelas inter-relações entre consumidores e feirantes. Essas relações proporcionam também uma troca de saberes e criação de laços sociais entre os referidos atores sociais.

Diante do exposto, objetivou-se por meio desse estudo caracterizar socialmente os consumidores de feiras livres da cidade de Maceió, Alagoas, Brasil acerca de suas percepções sobre agriculturas de base orgânica e agroecológica.

\section{PROCEDIMENTOS METODOLÓGICOS}

Com a finalidade de trazer o caráter de complementariedade entre as abordagens de pesquisa, neste estudo foram utilizados os enfoques qualitativo e quantitativo. A pesquisa foi realizada em duas feiras livres, ambas localizadas no município de Maceió, Alagoas, Brasil. Essas 
foram escolhidas por se tratarem das mais frequentadas pela população da cidade, bem como por se tratarem de apresentar maior diversificação de produtos, bem como maior área ocupada (ALMEIDA; FERREIRA NETO, 2017).

As visitas se deram diretamente para com os consumidores durante a realização das feiras, desse modo, os atores sociais da pesquisa foram entrevistados por meio de um questionário, de modo aleatório, sempre respeitando o interesse do mesmo em participar da pesquisa, onde o entrevistado foi esclarecido dos objetivos da pesquisa bem como da importância e papel de sua participação na mesma, a qual se constituiu na aplicação de questionários estruturados, que segundo Rover (2012) são compreendidas como procedimentos metodológicos que podem produzir ótimos resultados na realização da pesquisa social, mesmo que consideradas as diferentes restrições e particularidades de cada caso.

Assim, os questionários, elaborados pelos autores e com base em pesquisa anterior (ALMEIDA et al., 2018), compostos por 11 perguntas abertas e fechadas, foram subsídio para a coleta de informações referentes aos consumidores, tais como: escolaridade, idade, gênero, faixa etária, e perguntas diretamente relacionadas à percepção acerca do conhecimento entre agricultura de base orgânica e agroecológica. Assim a aplicação se deu de modo aleatório nas supracitadas feiras livres, onde o pesquisador (questionador) assinalava conforme resposta do entrevistado/questionado, sendo coletadas 180 entrevistas. Então, obtidas as informações, estas foram tabuladas e agrupadas (GIL, 2019) em planilhas no Microsoft Excel. Os dados quantitativos foram expressos em porcentagem (\%) sobre a amostra total e os dados qualitativos, como o caso de respostas não direcionadas, foram interpretados e discutidos com base em documentação e apoio teórico.

\section{RESULTADO E DISCUSSÃO}

Por meio dos dados levantados através da pesquisa de campo tendo como órtese o questionário semiestruturado, foi possível traçar um perfil dos consumidores de feiras livres em Maceió, Alagoas, Brasil. Nesse aspecto, em função a gênero e faixa etária, foi observado que o locus do estudo é caracterizado por uma maioria feminina, com idade diversificada, porém, sendo mais evidente a presença de mulheres com 20-24 anos e 45-69 (Figura 1), o que mostra uma tendência a pessoas com idades mais avançadas (45-69 anos de idade) frequentando o ambiente das feiras em estudo. Quanto aos homens, foi verificado faixa etária predominante de 30-49 anos. 
Figura 1 - Faixa etária (anos) (\%) em função de gênero de consumidores frequentadores de feiras livres na cidade de Maceió, Alagoas, Brasil.

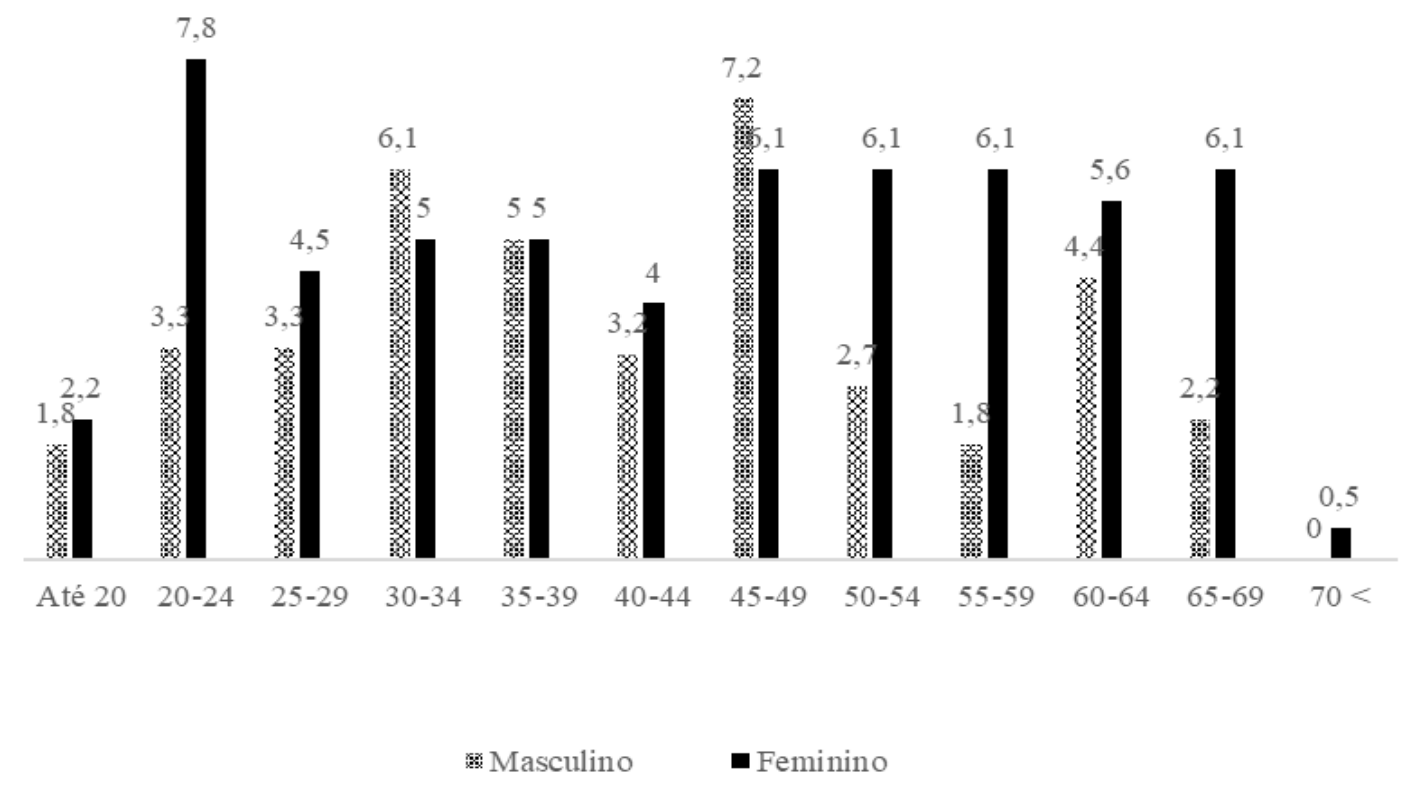

Fonte: Elaboração dos autores.

Analisando autores anteriores (ROCHA et al., 2012; BRANDÃO, et al., 2015; LOBO et al., 2020; LIMA et al., 2020) é possível perceber que a relação faixa etária x gênero é algo peculiar e intrínseco de cada localidade, não sendo uma característica específica de feiras livres. Nesse sentido, vê-se as diferenças entre trabalhos já publicados como pode ser observado em Rocha et al. (2012) que estudando feiras livres em Passo Fundo - Rio Grande do Sul, percebeu uma maior presença masculina entre os consumidores, com faixa etária acima dos 40 anos. Já Brandão et al. (2015) estudando feiras livres na região norte de Minas Gerais perceberam maior presença feminina com idade diversificada, assim como observado por Castro et al. (2020) que observaram maior frequência do gênero feminino em feira livre localizada em Sobral-CE.

Lobo et al. (2020) descrevem que a maior parcela de consumidores em feira livre do bairro da Jatiúca, Maceió-AL, é composto por sujeitos do gênero feminino com idade variando entre 21 a 70 anos. Dados semelhantes são descritos por Lima et al. (2020), onde os autores descrevem que majoritariamente a população de consumidores da feira livre itinerante no bairro Eustáquio Gomes, Maceió, AL é composta por mulheres.

Assim, pode-se afirmar que estes parâmetros são inerentes a cada localidade e especificidades sociais. As feiras aqui estudadas, embora localizadas em bairros distantes dos 
chamados "bairros nobres" são bem frequentadas por pessoas de outros bairros mais distantes, especialmente pela diversificação de produtos que podem ser encontrados.

Ao se analisar a escolaridade dos questionados, foi realizada uma comparação em função de gênero, onde foi detectado que estes possuem um perfil escolar em sua maioria com fundamental incompleto, seguido de ensino médio completo e ensino superior completo (Figura 2). Ademais, nota-se que as mulheres com menor escolaridade são aquelas com idades maiores e que com maior nível de letramento possuem idades menores, ou seja, isso demonstra que há uma mudança de cenário social em função da educação de mulheres, onde estas passaram por um período onde educação já foi inacessível às mulheres, especialmente aquelas de menor status social. Essas mudanças de paradigmas são fundamentais para a construção da sociedade mais justa, como também a interação desse público nas pautas que visem as questões ambientais e agrícolas, especialmente no que se trata de saberes saudáveis e sustentabilidade.

Figura 2 - Escolaridade (\%) de consumidores frequentadores de feiras livres em função de gênero em Maceió, Alagoas, Brasil.

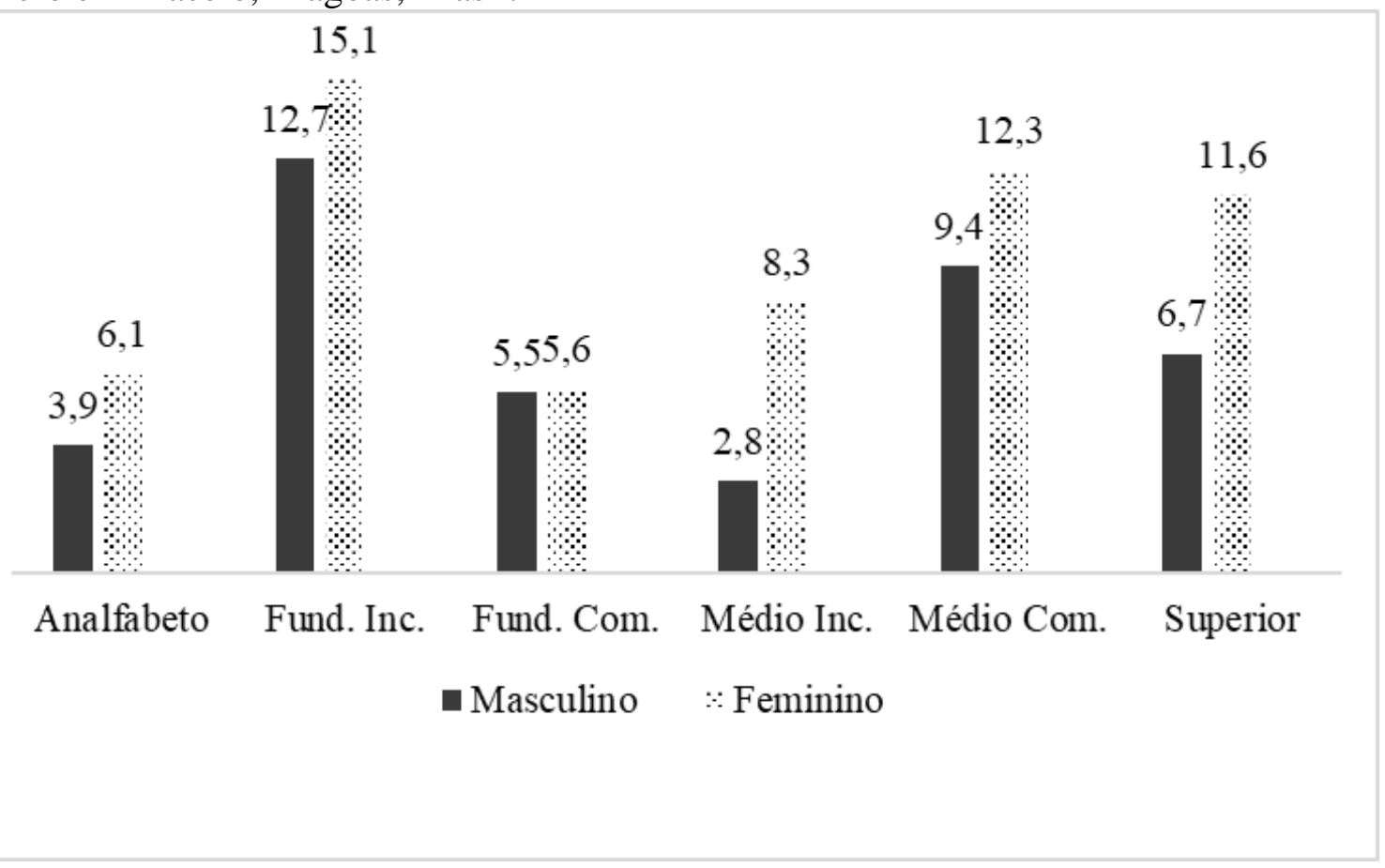

Fonte: Elaboração dos autores.

A escolaridade, em alguns casos, é um fator que pode ser considerado condicionante no que se trata da compreensão de determinados assuntos, como demonstrado por Almeida et al. (2018), onde feirantes entrevistados acerca da percepção de agriculturas discorriam sobre não conhecer as pautas de agroecologia e agricultura orgânica, sendo esse quadro, segundo eles, determinado pela baixa ou nula escolaridade. 
Cabe aqui frisar que além da escolaridade é necessário um conjunto de ações partindo da Academia para com a população, especialmente no tocante dos saberes saudáveis. Isso se dá pelo fato de que atualmente com a velocidade e volume de informações, é necessário estar sempre atento e crítico para aquilo que as mídias têm externado sobre a agricultura de um modo geral.

Quando questionados sobre a necessidade de redução do uso de agrotóxicos na agricultura, 89,44\% dos entrevistados responderam que sim e apenas 1,11\% não soube opinar (Figura 3). Essa parcela na qual não opinou é um reflexo da falta de aproximação para com o meio rural, mesmo que de modo indireto, como também podem sofrer influência dos mecanismos midiáticos, especialmente pelo excesso de informações constantemente disseminadas sobre agricultura, onde muitas dessas são financiadas por impérios agroalimentares gigantes do agronegócio.

Figura 3 - Percepção (\%) de consumidores frequentadores de feiras livres em Maceió, Alagoas, Brasil, sobre a redução do uso de agrotóxicos na agricultura.

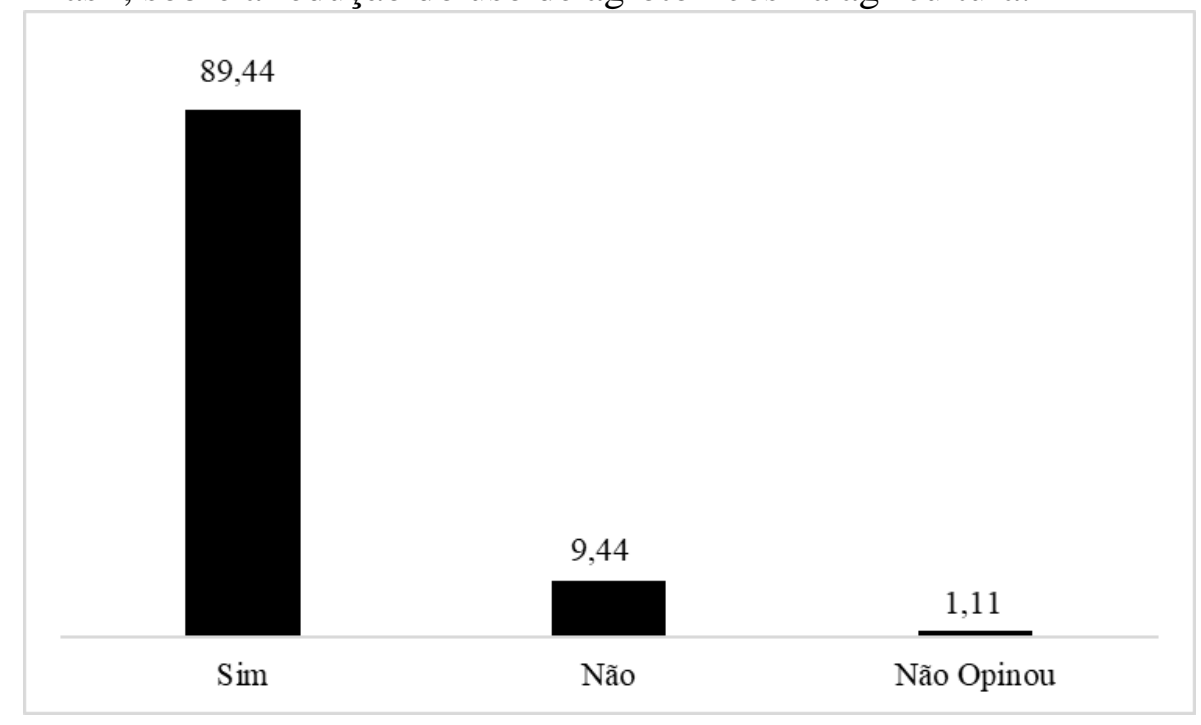

Fonte: Elaboração dos autores.

O crescimento da população mundial e os processos acelerados de urbanização, somados à elevação da renda e ao incentivo à produção e ao consumo, fizeram com que a demanda por alimentos tivesse aumento considerável na última década e projeta-se para 2025 que os países em desenvolvimento serão responsáveis por $96 \%$ do consumo de grãos e $88 \%$ de produtos de origem animal (OECD-FAO, 2017). Essa corrida desenfreada toma posse de recursos ambientais somados à degradação do meio ambiente. Isso faz com que os impérios agroalimentares sintam a necessidade de acelerar a produção agrícola, o que induz ao maior uso de moléculas nocivas ao meio ambiente e à agricultura. 
Um relatório publicado pela National Geographic Brazil por Damasio (2019) mostra a quantidade de moléculas (agrotóxicos) liberadas no Brasil até julho de 2019

Atualmente, 425 ingredientes ativos têm uso autorizado e 2.356 produtos estão liberados para comercialização no Brasil. Entre os pesticidas aprovados neste ano, 118 (41\%) são extrema ou altamente tóxicos e $32 \%$ não são permitidos na União Europeia. Foram aprovados ingredientes a base de duas novas moléculas, o sulfoxaflor e o florpirauxifenbenzil. Outros 32 novos ingredientes ativos esperam registro. Entre os pedidos, quatro ainda não foram aprovados em outros países, 19 já estão liberados nos Estados Unidos, 19 no Canadá, 18 na Austrália, 17 no Japão, 16 na União Europeia e 15 na Argentina, segundo a Associação Nacional de Defesa Vegetal (Andef).

Esses dados soam um alarme pelo fato de que destes ingredientes ativos liberados, a maior parte - os mais difundidos - são aqueles que apresentam risco à saúde humana e ao meio ambiente, porém, há moléculas biológicas, não nocivas, mas que não são difundidas nos veículos de informação, e em pouco número entre aqueles que são conhecidos como detentores do assunto. Nesse aspecto, 78,9\% dos entrevistados (Figura 4) alegaram que conhecem os riscos causados pelos agrotóxicos. Desses, a maioria afirma que o câncer é a principal patologia provocada pelo uso excessivo e indiscriminado dos agrotóxicos. 
Figura 4 - Percepção (\%) de consumidores frequentadores de feiras livres em Maceió, Alagoas, Brasil, sobre os danos causados pelo uso de agrotóxicos.

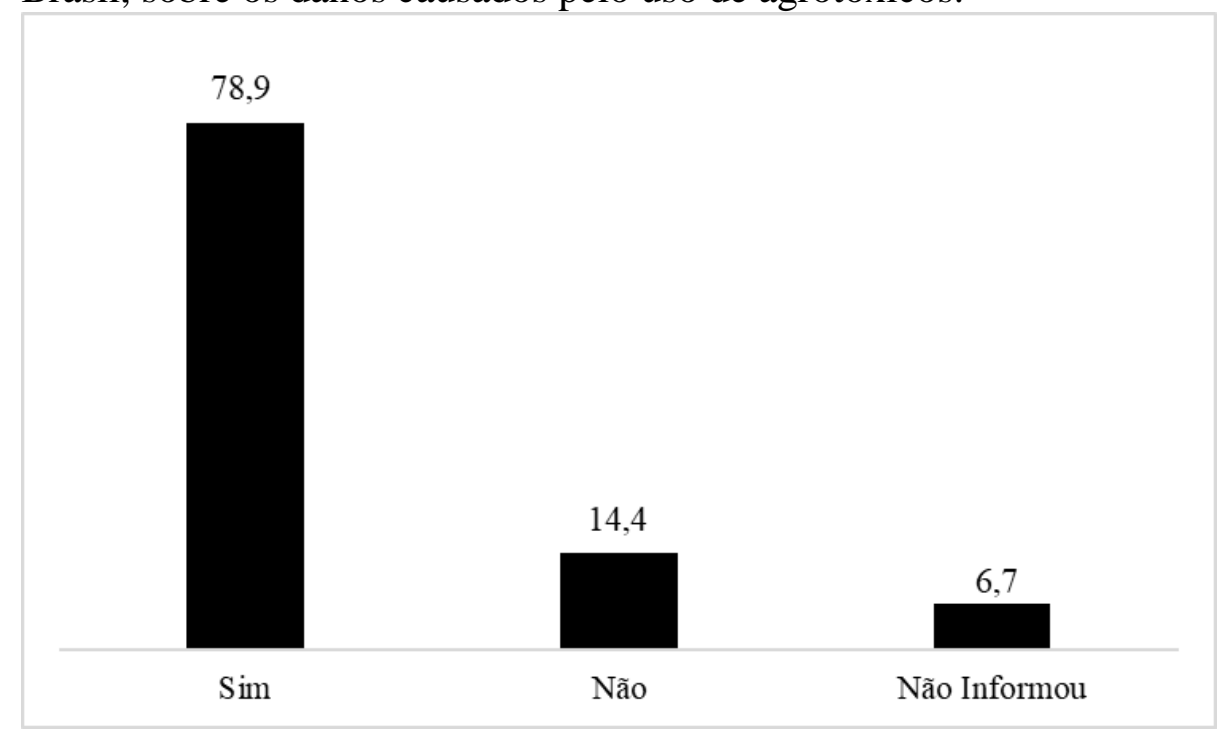

Fonte: Elaboração dos autores.

Segundo Pignati et al. (2017) as mais frequentes formas de intoxicação aguda por agrotóxicos são incidência de malformação fetal (intoxicação subaguda) e mortalidade por câncer infantojuvenil (intoxicação crônica). Esses danos na maioria das vezes são observados em trabalhadores rurais e seus familiares, os quais são expostos diariamente de forma direta e indireta a esses produtos. Ribas e Matsumura (2009) em seu trabalho afirmam que os danos ambientais causados por agrotóxicos podem ser na estrutura e fertilidade do solo, contaminação de águas fluviais e eliminação de organismos benéficos, como polinizadores, por exemplo.

Nesse segmento, a população tem repensado sobre o consumo de produtos livres de agrotóxicos ou redução do consumo sempre que possível. Logo, ao se indagar sobre a acessibilidade de produtos orgânicos ou agroecológicos, os entrevistados alegam que esse tipo de produto é de difícil acesso (Figura 5A), além de deixarem explícito que produtos orgânicos têm sido mais frequentemente encontrados em supermercados e com preços elevados, o que não atrai o consumidor. Entretanto, 57,77\% (Figura 5B) dos entrevistados afirmam que consomem ou já consumiram alimentos orgânicos ou agroecológicos. 
Figura 5 - Percepção (\%) de acessibilidade e consumo de produtos de base orgânica e agroecológica por consumidores frequentadores de feiras livres em Maceió, Alagoas, Brasil.
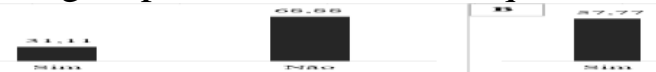

Fonte: Elaboração dos Autores.

A busca por qualidade de vida tem feito com que a população se mobilize para modificar seus hábitos alimentares, sendo assim, o consumo de alimentos orgânicos está expandindo à medida que a população se conscientiza sobre seus benefícios (VENANCIO; SILVA; ROSSI, 2017). Porém, essa realidade ainda é inerente às condições sociais e de acessibilidade a esses tipos de alimento, como demonstrado na atual pesquisa. Outro fato relevante para esse aspecto é a heterogeneidade do público estudado, o que reflete um dado sem tendências direcionadas. Ainda nesse raciocínio, é importante diferenciar agricultura de base orgânica e agricultura de base agroecológica, pois cada uma dessas possui suas peculiaridades, embora em momentos possam se unificar. Diante disso, observou-se que 17,77\% dos entrevistados (Figura 6) consideram as duas iguais, sem diferenciação, o que é também observado por pesquisa realizada por Almeida et al. (2018).

Figura 6 - Percepção (\%) de consumidores frequentadores de feiras livres em Maceió, Alagoas, Brasil sobre agricultura de base orgânica e agroecológica.

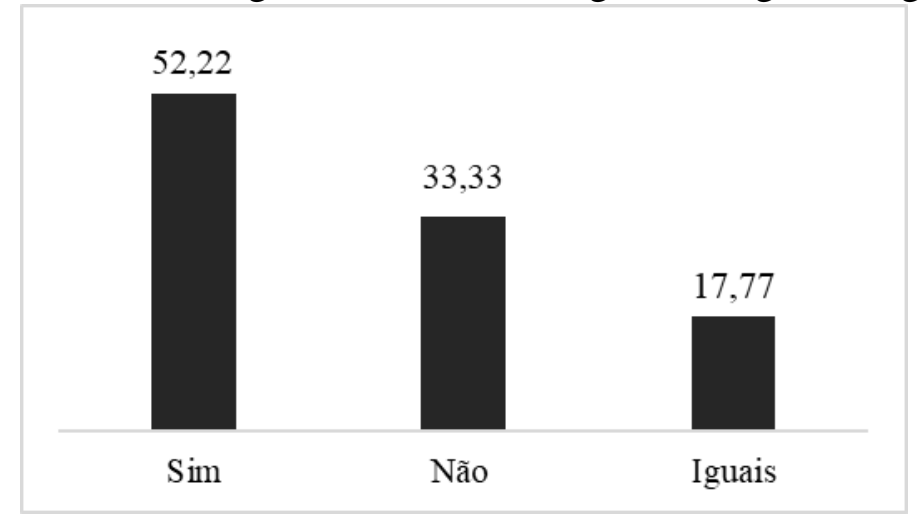

Fonte: Elaboração dos autores.

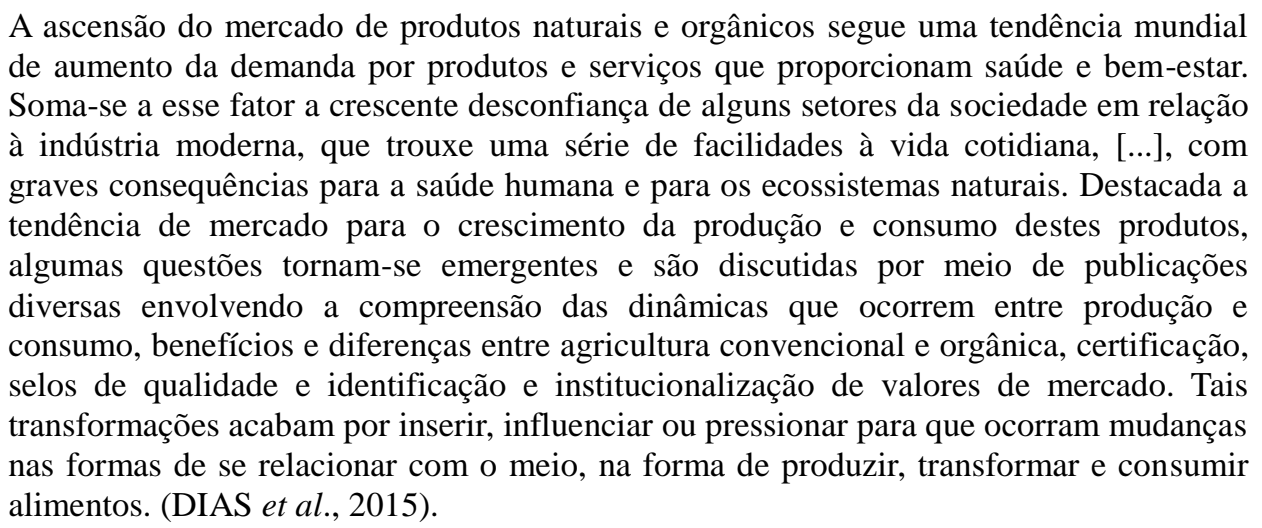


Nesse sentido, é fundamental a participação da sociedade nesses ambientes de discussão. Por outro lado, mesmo com a facilidade de acesso a tais debates, muitas vezes não são difundidos ou falta uma forte articulação para que essas discussões saiam das bolhas acadêmicas e adentrem a sociedade em todas as esferas. A exemplo, pode ser citada a liberação repentina de uma enorme quantidade de agrotóxicos, porém, não houve quaisquer debates entre governos, entidades e sociedade.

Portanto, a construção de saberes deve ter alicerce além dos teóricos, mas pela participatividade da comunidade. Por exemplo, desenvolvimento de materiais informativos sobre construção da agroecologia e de alimentação orgânica de modo palpável a toda a sociedade. Atualmente, temos a facilidade da internet para a difusão de informações adequadas em combate aos sensacionalismos e notícias inverídicas ou infundadas.

\section{CONCLUSÃO}

Por meio desse estudo conclui-se que a relação entre o perfil dos consumidores de feiras livres sobre a base de agricultura orgânica e agroecológica precisa ser ampliada, especialmente no contexto atual do mundo globalizado, acerca da agroecologia, sendo fundamental no entendimento entre produção, consumo e consequências ao ambiente, dentro dos espaços supracitados, no caso do estudo as feiras analisadas no município de Maceió - AL.

Vale ressaltar que as feiras livres observadas demonstram que seus consumidores apresentam todos os níveis de escolaridade e faixas etárias. A medida das faixas etárias examinadas corroboram que, quanto mais novo o consumidor maior o nível de escolaridade, o que permite um entendimento maior sobre conceitos de agroecologia, agricultura orgânica e saberes saudáveis.

Ademais, como assinalam os resultados, maioria dos consumidores pesquisados expõe a importância da redução no uso de agrotóxicos ao associá-los com a produção de alimentos e os danos causados, como doenças respiratórias e de pele. Esta análise mostra um dado importante e requer atenção para que seja introduzida nas feiras livres alimentos mais saudáveis a serem consumidos, pois atuam como propostas de comercialização dos produtos e o reconhecimento e diferenças da agricultura de base orgânica e agroecológica que reafirmem no espaço de produção e reprodução da sociedade e o desenvolvimento de práticas mais sustentáveis.

\section{REFERÊNCIAS}

ALMEIDA, L. C.; SILVA, J. M.; ARAÚJO, R. G. V.; SILVA, C. S.; LIMA, J. R. B.; CRISTO, C. C. N.; SANTOS, T. M. C.; COSTA, J. H. Perfil social e percepção de feirantes sobre agricultura 
de base orgânica e agroecológica. Ciência Agrícola, Rio Largo, v. 16, número suplementar, p. 71-74, 2018. https://doi.org/10.28998/rca.v16i0.6591

ALMEIDA, A. J. P.; FERREIRA NETO, J. V. Mapeamento de áreas impermeáveis para caracterização da urbanização da bacia endorreica do Tabuleiro do Martins, Maceió/Al. Revista Contexto Geográfico, Maceió, v. 2. n. 3, p. 100-109, 2017.

https://doi.org/10.28998/contegeo.v2i3.6138

ALTIERI, M. A. Agroecologia: as bases científicas da agricultura alternativa. 2 ed. Rio de Janeiro: PTA-FASE, 1989. 240p.

ANDRADE, J. A. V. Economia urbana e articulação dos setores populares: o caso do centro comercial e de serviços popular do bairro do Jacintinho Maceió - AL. 2012, $123 \mathrm{f}$.

Dissertação (Mestrado em Economia Aplicada). Universidade Federal de Alagoas, Maceió. 2012.

AQUINO, A. M.; ASSIS, R. L. Agroecologia: princípios e técnicas para uma agricultura orgânica sustentável. Brasília: Embrapa Informação Tecnológica, 2005. 517p.

BRANDÃO, A. A.; COSTA, C. A.; GALIZONI, F. M.; CAVALCANTE, T. F. M.; NEVES, A. C. Perfil socioeconômico dos consumidores de hortaliças em feiras livres na microrregião de Januária. Horticultura Brasileira, v. 33, n. 1, p. 119-124, 2015. https://doi.org/10.1590/S0102053620150000100019

BRANDENBURG, A. Movimento agroecológico: trajetória, contradições e perspectivas.

Desenvolvimento e Meio Ambiente, Curitiba, v. 6, p. 11-28, 2002.

http://dx.doi.org/10.5380/dma.v6i0.22125

CAMPANHOLA, C.; VALARINI, P. J. A agricultura orgânica e seu potencial para o pequeno agricultor. Cadernos de Ciência e Tecnologia, Brasília, v. 18, n. 3, p. 69-101, 2001.

http://dx.doi.org/10.35977/0104-1096.cct2001.v18.8851

CANDIOTTO, L. Z. P. Agroecologia: Conceitos, princípios e sua multidimensionalidade.

Ambientes Revista de Geografia e Ecologia Política, Francisco Beltrão, v. 2, n. 2, p. 25-75, 2020. https://doi.org/10.48075/amb.v2i2.26583

CASTRO, M. M.; CATRO, T. M.; ALVES, M. V. B. D.; ANGELIM, A. M.; FERNANDES, F. E. P.; SOUSA, K. M. P. Perfil e percepção dos consumidores de produtos agroecológicos em feira livre. Cadernos Agroecológicos, s.1., v. 15, n. 2, 2020.

DAMASIO, K. Liberação recorde reacende debate sobre uso de agrotóxicos no Brasil. 2019. Disponível em: <https://www.nationalgeographicbrasil.com/meio-ambiente/2019/07/liberacaorecorde-reacende-debate-sobre-uso-de-agrotoxicos-no-brasil-entenda $>$. Acesso em 10 de agosto de 2020.

GIL, A. C. Métodos e Técnicas de Pesquisa Social. 5. ed., São Paulo: Atlas, 2019.

JESUS, E. L. de. Da agricultura alternativa à agroecologia: para além das disputas conceituais. Agricultura Sustentável, Jaguariúna, v. 3 , p. 3-27, 1996.

LIMA, E. F. L.; SANTOS, T. M. C.; SILVA, J. M.; COSTA, J. H. Q. Os consumidores de feira agroecológica itinerante em Maceió, Alagoas. Cadernos Agroecológicos, s.l., v. 15, n. 2, 2020. 
LOBO, R. L. L.; CAVAlCANTE, M.; ALBUQUERQUE, K. S. P.; CALHEIROS, A. S. Perfil dos comerciantes e consumidores da feira livre da Jatiúca - Maceió/AL. Cadernos

Agroecológicos, s.1., v. 15, n. 2, 2020.

NORDER, L. A.; LAMINE, C.; BELLON, S.; BRANDENBURG, A. AGROECOLOGIA: POLISSEMIA, PLURALISMO E CONTROVÉRSIAS. Ambiente \& Sociedade, São Paulo, v.19, n. 3, p.1-20, Set. 2016. https://doi.org/10.1590/1809-4422ASOC129711V1932016

OECD-FAO. Agricultural outlook 2017-2026. Paris: OECD Publishing, 2017. Disponível em: $<$ http://www.fao.org/3/a-i7465e.pdf $>$. Acesso em: 1 de agosto de 2020.

ORMOND, J. G. P.; PAULA, S. R. L.; FAVERET FILHO, P. S. C.; ROCHA, L. T. M. Agricultura Orgânica: quando o passado é futuro. BNDES Setorial, Rio de Janeiro, n. 15, p. 3-34, mar. 2002.

PAULINO, E. T.; ALMEIDA, R. A. de. A natureza da economia camponesa: divergências e convergências. In: PAULINO, E. T.; ALMEIDA, R. A. de. Terra e Território: A questão camponesa no capitalismo. São Paulo: Expressão Popular, 2010.

PIGNATI, W. A.; LIMA, F. A. N. S.; LARA, S. S.; CORREA, M. L. M. BARBOSA, J. R.; LEÃO, L. H. C.; PIGNATTI, M. G. Distribuição espacial do uso de agrotóxicos no Brasil: uma ferramenta para a Vigilância em Saúde. Ciência \& Saúde Coletiva, Rio de Janeiro, v. 22, n. 10, p. 3281-3293, 2017. https://doi.org/10.1590/1413-812320172210.17742017

PRIMAVESI, A. M. Agroecologia: ecosfera, tecnosfera e agricultura. São Paulo: Nobel, 1997.

REIS, N. J. R.; TALGA, D. O. Mídia e Agrotóxicos no Agronegócio do Capital, Envenenamento Humano e Simbólico do Planeta. Razón y Palabra, v. 20, n. 94, p. 770-790, 2016.

RIBAS, P. P.; MATSUMURA, A. T. S. A química dos agrotóxicos: impacto sobre a saúde e meio ambiente. Revista Liberato, Novo Hamburgo, v. 10, n. 14, p. 149-158, jul./dez. 2009.

10.31514/rliberato.2009v10n14.p149

ROCHA, H. C.; COSTA, C.; CASTOLDI, F. 1.; CECCHETTI, D.; CALVETI, E. O.; LODI, B. S. Perfil socioeconômico dos feirantes e consumidores da Feira do Produtor de Passo Fundo, RS. Ciência Rural, Santa Maria, v. 40, n. 12, p. 2593-2597, 2010. https://doi.org/10.1590/S010384782010005000196

ROVER, J. O. O método científico em ciências sociais: dos documentos, questionários e entrevistas à análise de enunciados. Revista Grifos, Chapecó, v. 21, n. 32/33, p. 14-28, 2012. $10.22295 /$ grifos.v21i32/33.2394

RUFINO, J. L. dos S. Origem e conceito de agronegócio. Informe Agropecuário, Belo Horizonte, v. 20, n. 199, p. 17-19, 1999.

SILVA, A. K.; CRISTO, C. C. N.; MEDEIROS, M. S.; COSTA, J. H. Q.; ALBUQUERQUE, C. F.; SILVA, J. M. Reforma agrária e processos produtivos no Assentamento Canafístula, Jacuípe, AL. Movimentos Sociais e Dinâmicas Espaciais, Recife, v. 9, p. 88-105, 2020.

https://doi.org/10.46802/rmsde.v9i1.245041

VENANCIO, L.; SILVA, V. G.; ROSSI, M. S. C. Perfil dos consumidores de alimentos orgânicos das feiras agroecológicas do estado de São Paulo. Nutrivisa - Revista de Nutrição e Vigilância em Saúde, v. 4, n. 2, p. 27-37, jul./out., 2017. 
YANAMOTO, A. T. V.; TAVARES, C. A.; FREIXÊDA, V. M. Cartilha consumidor é um ato político!: rede guandu - produção e consumo responsáveis. Piracicaba: Instituto Terra Mater, 2012. 